\title{
CRESCIMENTO E SINTOMAS VISUAIS DE DEFICÊNCIAS DE MICRONUTRIENTES EM UMBUZEIROS ${ }^{1}$
}

\author{
ORLANDO SÍLVIO CAIRES NEVES², JOSÉ ROBERTO DE SÁ ${ }^{3}$, JANICE GUEDES DE CARVALHO
}

\begin{abstract}
RESUMO - O efeito da omissão de micronutrientes no crescimento e na manifestação de sintomas visuais de deficiência em mudas de umbuzeiro, cultivadas em solução nutritiva, foi avaliado nesse trabalho. O delineamento experimental utilizado foi o inteiramente casualizado, com quatro repetições e sete tratamentos, sendo estes: completo (todos os nutrientes), com omissão individual de B, Cu, Fe, Mn e Zn e omissão simultânea de Zn e Cu. A falta de B, Cu, Fe, Mn e Zn na solução nutritiva levou a um comprometimento no desenvolvimento das plantas, induzindo, inclusive, alterações morfológicas com sintomas característicos de deficiência nutricional de cada nutriente. O umbuzeiro mostrou-se mais exigente em B, Fe e Zn na fase inicial de crescimento do que em $\mathrm{Mn}$ e $\mathrm{Cu}$. A redução na matéria seca total das mudas de umbuzeiro foi influenciada na seguinte ordem: $\mathrm{Fe}>\mathrm{B}>\mathrm{Zn}$ $>\mathrm{Zn}+\mathrm{Cu}>\mathrm{Cu}>\mathrm{Mn}$.
\end{abstract}

Termos para indexação: Spondias tuberosa, nutrição mineral e solução nutritiva.

\section{GROWTH AND VISUAL SYMPTOMS OF MICRONUTRIENTS DEFICIENCY IN UMBUZEIRO}

ABSTRACT - The effect of micronutrient omission on growth and nutritional deficiency symptoms in umbuzeiro seedlings cultivated in nutrient solution was evaluated in this work. The experimental design was completely randomized with four replication and seven treatments, being them: complete (all the nutrients), with individual omission of B, Cu, Fe, Mn and $\mathrm{Zn}$ and simultaneous omission of $\mathrm{Zn}$ and $\mathrm{Cu}$. The absence of B, Cu, Fe, $\mathrm{Mn}$ and $\mathrm{Zn}$ in the nutrient solution implicated on the reduction plants development inducing morphologic alterations with characteristic symptoms of nutritional deficiency of each nutrient. The umbuzeiro was shown more demanding in B, Fe and $\mathrm{Zn}$ in the initial phase of growth than $\mathrm{Mn}$ and $\mathrm{Cu}$. The reduction in the total dry matter of the umbuzeiro seedlings was influenced in the following order: $\mathrm{Fe}>\mathrm{B}>\mathrm{Zn}>\mathrm{Zn}+\mathrm{Cu}>\mathrm{Cu}>\mathrm{Mn}$.

Index terms: Spondias tuberosa, mineral nutrition and nutrient solution.

\section{INTRODUÇÃO}

O umbuzeiro (Spondias tuberosa Arr. Cam.) é uma espécie xerófita, caducifólia, originária das zonas menos chuvosas da região Nordeste do Brasil e do norte do Estado de Minas Gerais e pertence à família Anacardiaceae. Devido às suas defesas fisiológicas, a árvore do umbuzeiro é resistente à seca (Gondim et al., 1991).

Apesar de sua distribuição ser dispersa, o umbuzeiro se consagra como espécie frutífera de grande importância econômica, social e ecológica, cuja cultura representa uma fonte de renda adicional no período da entressafra, contribuindo com a metade da renda média anual dos agricultores nas áreas de coleta (Araújo et al., 2000).

De acordo com o Censo frutícola da CODEVASF (2001), a área total plantada com umbuzeiros (excetuando as de plantas nativas) é de 509,4 ha, sendo 0,5 ha em formação, 23,0 ha em produção crescente, 332,8 ha em produção plena e 153,1 ha em declínio de produção. É importante frisar que a área plantada cresceu consideravelmente nos dois últimos anos.

Deficiências de micronutrientes, tanto em culturas anuais como em perenes nos solos brasileiros, são muito comuns, ocorrendo, principalmente, em função da matéria orgânica do solo, do pH do solo e da calagem excessiva (Malavolta et al., 1997). Segundo Malavolta (1986), uma planta cultivada em solo pobre em micronutrientes pode apresentar comprometimento no crescimento e, conseqüentemente, queda ( $20 \%$ a $30 \%$ ) de produção.

A falta ou excesso de um dado elemento é traduzida em anormalidades visíveis, que são típicas de cada elemento. O motivo pelo qual o sintoma é típico, deve-se ao fato de que um dado nutriente exerce sempre as mesmas funções, qualquer que seja a espécie de planta. Devese ter em mente, entretanto, que, antes da manifestação visível da deficiência, o crescimento e a produção já poderão estar limitados: é o que se chama de "fome escondida". O sintoma visível é o fim de uma série de eventos, que têm início com alterações em nível molecular, avança para modificações subcelulares, intensifica-se com alterações celulares e atinge o tecido, modificando-o, ocasionando a expressão de sintomas visíveis (Malavolta et al., 1997).

O boro afeta o crescimento meristemático, onde sua falta leva a um desenvolvimento precário das pontas das radicelas das pontas dos ramos; ao que parece, isso deve-se à necessidade de boro para a síntese de bases nitrogenadas, como a uracila, componente essencial do RNA (Marschner, 1995). O Fe, dentre outras funções na planta, participa da biossíntese de clorofila, e a sua falta afeta o crescimento da mesma; o $\mathrm{Cu}$ participa de ativação enzimática, da fotossíntese e tem influência no processo de fixação biológica de N; o Mn também participa da fotossíntese, agindo na liberação fotoquímica do $\mathrm{O}_{2}$ e faz parte da redutase do nitrato, e o Zn participa, principalmente, na síntese do AIA e na divisão celular (Malavolta et al., 1997).

O objetivo deste trabalho foi avaliar o crescimento e caracterizar a sintomatologia de deficiências de micronutrientes em mudas de umbuzeiro.

\section{MATERIAL E MÉTODOS}

O experimento foi realizado em casa de vegetação do Departamento de Ciência do Solo da Universidade Federal de Lavras (Lavras-MG), definida geograficamente pelas coordenadas de $21^{\circ} 14^{\prime}$ de latitude sul e $45^{\circ} 00^{\prime}$ de longitude oeste, altitude de $910 \mathrm{~m}$ e conduzido de outubro de 2002 a janeiro de 2003.

O delineamento experimental foi o inteiramente casualizado, com quatro repetições e sete tratamentos, representados por: solução (Hoagland \& Arnon, 1950) completa (testemunha), solução nutritiva menos B (-B), solução nutritiva menos $\mathrm{Cu}(-\mathrm{Cu})$, solução nutritiva menos $\mathrm{Fe}(-\mathrm{Fe})$, solução nutritiva menos Mn (-Mn), solução nutritiva menos Zn $(-\mathrm{Zn})$ e solução nutritiva com omissão de $\mathrm{Cu}$ e $\mathrm{Zn}(\mathrm{Cu}+\mathrm{Zn})$. Cada parcela foi constituída por uma planta por vaso de $3 \mathrm{~L}$. As mudas utilizadas foram oriundas de sementes, sendo germinadas em vermiculita. As sementes passaram pelo processo de quebra de dormência através de escarificação mecânica, conforme recomendação de Nascimento et al.

${ }^{1}$ (Trabalho 014/2004). Recebido: 12/02/2004. Aceito para publicação: 04/08/2004.

${ }^{2}$ Doutorando em Solos e Nutrição de Plantas, DCS - UFLA, Bolsista CNPq. E-mail: orlandosilvio@ ufla.br, Fone (0xx35)38216741. Rua Sílvio Menicucci, 1510, ap. 102, Centenário. Lavras-MG, CEP 37.200.000.

${ }^{3}$ Doutorando em Solos e Nutrição de Plantas, DCS - UFLA, Bolsista CNPq. E-mail: robertsaj@ bol.com.br. Fone (0xx35)38213189. UFLA/DCS, CP 37, CEP 37.200.000.

${ }_{4}^{4}$ Professora Titular do Departamento de Ciência do Solo da Universidade Federal de Lavras-MG. E-mail: janicegc @ ufla.br. Fone (0xx35)38291269. UFLA/DCS, CP 37, CEP 37.200.000. 
TABELA 1 - Altura, diâmetro do caule, matéria seca de raiz, caule, folha e total, relação parte aérea/raiz e crescimento relativo (CR) de mudas de umbuzeiro após 75 dias da aplicação dos diferentes tratamentos ${ }^{1}$. Lavras, 2002-2003.

\begin{tabular}{|c|c|c|c|c|c|c|c|c|}
\hline Tratamento & $\begin{array}{c}\text { Altura } \\
(\mathrm{cm})\end{array}$ & $\begin{array}{c}\text { Diâmetro } \\
(\mathrm{mm})\end{array}$ & $\begin{array}{l}\text { Raiz } \\
------\end{array}$ & $\begin{array}{l}\text { Caule } \\
-----g\end{array}$ & Folha & $\begin{array}{c}\text { Total } \\
\end{array}$ & $\mathrm{PA} / \mathrm{R}$ & $\begin{array}{l}\mathrm{CR}^{*} \\
(\%)\end{array}$ \\
\hline Completo & $120,5 \mathrm{a}$ & $13,6 a b c$ & 7,21ab & $33,15 a$ & $14,24 a$ & $54,61 \mathrm{a}$ & $6,67 \mathrm{ab}$ & 100,0 \\
\hline$-B$ & $61,4 \mathrm{c}$ & $11,0 \mathrm{~cd}$ & $5,28 b c$ & $12,21 \mathrm{~d}$ & $4,42 \mathrm{~cd}$ & $22,92 \mathrm{c}$ & $3,36 \mathrm{c}$ & 42,0 \\
\hline$-\mathrm{Cu}$ & $79,0 \mathrm{bc}$ & $14,4 \mathrm{ab}$ & $7,12 \mathrm{ab}$ & $30,66 a b$ & $13,9 \mathrm{a}$ & $51,69 a$ & $6,32 \mathrm{ab}$ & 94,7 \\
\hline$-\mathrm{Fe}$ & $62,9 \mathrm{c}$ & $9,4 d$ & $3,92 \mathrm{c}$ & $6,92 d$ & $2,84 d$ & $13,69 \mathrm{c}$ & $2,50 \mathrm{c}$ & 25,1 \\
\hline - Mn & $98,7 b$ & $16,1 \mathrm{a}$ & $7,93 a$ & $33,90 a$ & $12,63 a$ & $54,46 a$ & $5,86 \mathrm{ab}$ & 99,7 \\
\hline$-\mathrm{Zn}$ & $93,7 b$ & $12,2 \mathrm{bcd}$ & $5,73 \mathrm{bc}$ & $23,78 \mathrm{c}$ & $7,58 \mathrm{bc}$ & $37,10 \mathrm{~b}$ & $5,56 \mathrm{~b}$ & 67,9 \\
\hline$-(\mathrm{Zn}+\mathrm{Cu})$ & $95,5 \mathrm{bc}$ & $12,6 \mathrm{bcd}$ & $5,25 \mathrm{bc}$ & $24,56 b c$ & $11,17 \mathrm{ab}$ & $40,98 \mathrm{~b}$ & $6,97 \mathrm{a}$ & 75,0 \\
\hline D.M.S. & 21,8 & 3,2 & 2,1 & 6,4 & 4,0 & 11,5 & 1,4 & $\overline{-----}$ \\
\hline C.V. $(\%)$ & 10,9 & 10,9 & 14,8 & 11,8 & 18,1 & 39,3 & 11,2 & ----- \\
\hline
\end{tabular}

${ }^{1}$ Médias seguidas pela mesma letra na vertical não diferem significativamente, a 5\% de probabilidade, pelo teste Tukey.

*Referente à matéria seca total.

(2000). Quinze dias após a germinação, as mudas foram transferidas para solução nutritiva completa com 25; 50 e $100 \%$ da sua força iônica, durante período de 15 dias em cada concentração, respectivamente. Após o período de aclimatação, aplicaram-se os tratamentos onde foram omitidos os micronutrientes. As soluções foram trocadas quinzenalmente durante os 75 dias de condução do experimento.

Após a medida da altura $(\mathrm{cm})$ e o diâmetro da base dos caules $(\mathrm{mm})$, as plantas foram colhidas, separadas em raiz, caule e folha, e secadas em estufa com circulação forçada de ar, a $60-70^{\circ} \mathrm{C}$, até peso constante, para a determinação do peso da matéria seca e pelo somatório dos pesos da raiz, do caule e das folhas, o peso total da planta. A relação parte aérea : raiz (PA/R) foi calculada dividindo-se o peso seco da parte aérea (folha + caule) pelo peso seco de raiz.

O efeito relativo foi calculado pelo método de porcentagem de suficiência ou produção relativa (Raij, 1991), adaptado para a determinação do "crescimento relativo" (CR), segundo a fórmula:

$\mathbf{C R}=$ Tratamento com nutriente omitido $\mathrm{x} 100$ Tratamento completo

Os tratamentos que manifestaram os sintomas visuais de deficiência antes de completados os 75 dias de condução do experimento foram colhidos, visando, com isso, a reduzir perdas de material para análise.

Os dados obtidos foram analisados estatisticamente pelo teste $\mathrm{F}$ e, quando verificadas diferenças significativas, as médias foram comparadas pelo teste Tukey ( $\mathrm{p}<0,05)$, conforme descrito em PimentelGomes (1990). Para a realização dos cálculos estatísticos, foi utilizado o Programa Computacional Sisvar (Ferreira, 2000).

\section{RESULTADOS E DISCUSSÃO}

Efeitos no desenvolvimento - Os resultados da altura $(\mathrm{cm})$ e do diâmetro do caule $(\mathrm{mm})$ das mudas de umbuzeiro, nos diferentes tratamentos, são apresentados na Tabela 1. Conforme análise estatística dos dados, verificou-se que a omissão dos micronutrientes reduziu a altura das plantas, sendo o $\mathrm{B}$ e o $\mathrm{Fe}$ os que mais comprometeram o desenvolvimento em altura das mudas, quando comparados com o tratamento completo.

Em relação ao diâmetro, as plantas cultivadas com omissão de Fe e B apresentaram caules menos espessos, porém, não diferindo significativamente daquelas cultivadas na falta simultânea de $\mathrm{Zn}$ e $\mathrm{Cu}$ $(\mathrm{Zn}+\mathrm{Cu})$ e apenas $\mathrm{Zn}(-\mathrm{Zn})$. Isso parece indicar maior exigência em Fe e $\mathrm{B}$ na fase inicial de desenvolvimento das mudas, já que eles foram limitantes ao crescimento em altura. O maior diâmetro do caule foi apresentado pelas mudas do tratamento sem $\mathrm{Mn}$, cujos valores não diferiram significativamente daqueles apresentados no tratamento completo e menos $\mathrm{Cu}$. Nas plantas do tratamento menos Mn, o caule, na sua parte basal, apresentou um engrossamento, caracterizando possivelmente a expressão de sintoma de deficiência, particularmente observado neste experimento.

As omissões de B, Fe, $\mathrm{Zn}$ e $\mathrm{Zn}+\mathrm{Cu}$ ocasionaram, ainda, um decréscimo na produção de matéria seca de raiz e caule; já para as folhas, a redução foi maior quando não se adicionaram B, Fe ou Zn. Em relação ao $\mathrm{Mn}$ e ao $\mathrm{Cu}$, a matéria seca de raiz, caule e total das plantas não diferiu significativamente do tratamento completo. Isso parece decorrer do fato de o $\mathrm{Mn}$ e de o $\mathrm{Cu}$ terem sido os últimos nutrientes a apresentarem sintomas visuais de deficiência, indicando menor exigência do umbuzeiro, na fase de muda, desses nutrientes em relação aos demais estudados.

Os efeitos das deficiências dos micronutrientes, na produção de matéria seca total, induziram a seguinte ordem de redução: $\mathrm{Fe}>\mathrm{B}>\mathrm{Zn}>$ $\mathrm{Zn}+\mathrm{Cu}>\mathrm{Cu}>\mathrm{Mn}$, indicando mais uma vez que o desenvolvimento da planta, durante o período experimental, foi menos afetado pela omissão de $\mathrm{Mn}$ e de $\mathrm{Cu}$ do que pela omissão de Fe. Trabalhando com mudas de goiabeira, cultivadas em solução nutritiva, Salvador et al. (1999) encontraram resultados semelhantes quando avaliaram a deficiência de micronutrientes. Verificaram que a omissão dos micronutrientes afetou negativamente $\mathrm{o}$ desenvolvimento das mudas na seguinte ordem: $\mathrm{Fe}>\mathrm{Cu}>\mathrm{B}>\mathrm{Zn}>\mathrm{Mn}$, sendo o Mn o micronutriente que menos influenciou no desenvolvimento da goiabeira.. Em plantas de andiroba, Martins et al. (2000) verificaram que, em ordem crescente, os micronutrientes que mais afetaram $\mathrm{o}$ desenvolvimento das mudas, foram: $\mathrm{B}>\mathrm{Mn}>\mathrm{Cu}$, Fe e $\mathrm{Zn}$.

Os resultados da Tabela 1 mostram que a relação parte aérea/ raiz foi menor nos tratamentos menos $\mathrm{B}$ e menos $\mathrm{Fe}$, indicando ter havido maior redução na produção da parte aérea em relação à produção das raízes. A maior participação da parte aérea nessa redução fica evidenciada quando se observam os valores de massa seca produzida no tratamento completo, que diminuíram em aproximadamente $65 \%$ e $79 \%$ nos tratamentos sem adição de $\mathrm{B}$ e Fe, respectivamente, enquanto, em relação às raízes, essas reduções foram de $27 \%$ e $46 \%$.

$\mathrm{O}$ crescimento relativo foi calculado em relação ao tratamento completo, onde a produção de matéria seca total foi maior, permitindo verificar que o total de matéria seca produzida pelas mudas de umbuzeiro nos tratamentos sem B e sem Fe foi inferior a 50\%, sendo, respectivamente, de $25,1 \%$ e $42,0 \%$ do total produzido no tratamento completo. As plantas deficientes em $\mathrm{Zn}$ ou em $\mathrm{Zn}+\mathrm{Cu}$ apresentaram um CR entre 50 e $75 \%$, com valores reais de 67,9 e $75 \%$, respectivamente, e nas deficientes em $\mathrm{Cu}$ ou $\mathrm{Mn}$, as produções relativas de matéria seca total apresentaram-se acima de $75 \%$. O CR das plantas deficientes em $\mathrm{Cu}$ foi de $94,7 \%$ e das deficientes em $\mathrm{Mn}$ foi de 99,7\%. Estudando a limitação nutricional de um Latossolo Vermelho distrófico para umbuzeiros do norte de Minas Gerais, Silva et al. (2002) verificaram que, naquelas condições, os micronutrientes que mais limitaram o crescimento das plantas foram o $\mathrm{B}$ e o $\mathrm{Zn}$, resultados esses que mostram certa concordância com os apresentados na Tabela 1.

Pelos dados apresentados, percebeu-se que o umbuzeiro é mais exigente em $\mathrm{Zn}$ do que em $\mathrm{Cu}$, fato que fica mais evidenciado quando se analisa o crescimento relativo das plantas cultivadas na omissão simultânea de $\mathrm{Zn}$ e Cu e as compara com as cultivadas com omissão de $\mathrm{Zn}$ ou $\mathrm{Cu}$, isoladamente, onde os valores de $\mathrm{CR}$ se situam intermediariamente àqueles. 

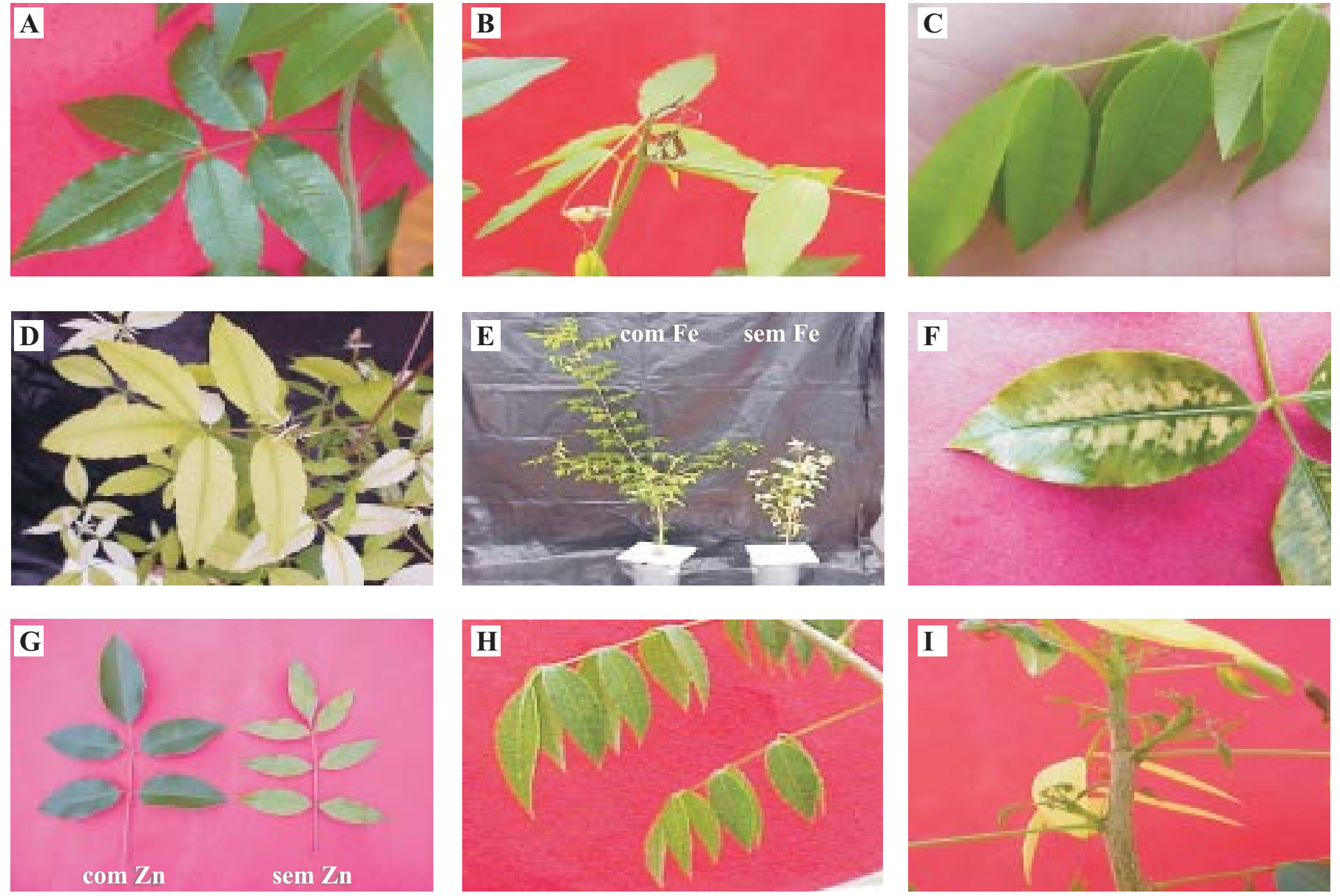

FIGURA 1 - Mudas de umbuzeiro submetida à omissão de micronutrientes: (A) (completa); (B) ausência de B; (C) ausência de Cu; (D) ausência de Fe; (E) plantas do tratamento com Fe e sem Fe; (F) ausência de Mn; (G) folhas de plantas dos tratamentos com Zn e sem Zn; (H e I) ausência simultânea de $\mathrm{Cu}$ e Zn.

\section{umbuzeiro}

\section{Sintomas visuais de deficiências de micronutrientes em}

As plantas que se desenvolveram nos tratamentos com omissão de micronutrientes, na solução nutritiva, apresentaram sintomas visuais de deficiências nas folhas, sintomas estes ausentes no tratamento completo (Figura $1 \mathrm{~A}$ ). A ordem cronológica de aparecimento desses sintomas foi a seguinte: $\mathrm{B}, \mathrm{Fe}, \mathrm{Zn}+\mathrm{Cu}, \mathrm{Zn}, \mathrm{Mn}$ e $\mathrm{Cu}$. Essa ordem é bem semelhante à descrita por Salvador et al. (1999), que trabalharam com mudas de goiabeira, em solução nutritiva.

Deficiência de boro - Os sintomas de deficiências começaram a aparecer nitidamente a partir do $20^{\circ}$ dia do início do tratamento, sendo as plantas colhidas aos 50 dias. A deficiência foi observada nas folhas mais jovens, que apresentaram leve clorose internerval, posteriormente evoluindo do centro para as bordas das folhas. Em seguida, essas folhas tornaram-se amareladas, destacando-se um fundo levemente clorótico. Essas folhas se encurvaram e se retorceram para baixo, resultando em acentuada queda dos primeiros pares de folhas, persistindo, entretanto, as mais velhas. A omissão do B induziu, ainda, a morte dos pontos vegetativos apicais (Figura $1 \mathrm{~B}$ ), provocando o secamento dos ápices de maneira descendente (dieback). A deficiência de B causou a formação de folhas menores e mais espessas em relação às folhas consideradas normais.

Deficiência de cobre - Aos 60 dias após o início do tratamento, foram observados os primeiros sintomas de deficiência do nutriente e, aos 75 dias, as mesmas foram colhidas; esses foram representados, inicialmente, por áreas cloróticas, esparsas nas folhas mais novas, que foram se agravando no decorrer do experimento. Os limbos foliares passaram a mostrar alterações morfológicas com as folhas posicionandose verticalmente, o que é comumente denominado de "orelha-de-zebu", conforme Figura $1 \mathrm{C}$. As plantas deficientes em Cu também acabaram por emitir gemas vegetativas axilares múltiplas, dando origem a brotações com folhas diminutas.
Deficiência de ferro - Aos 30 dias, a omissão de Fe causou alterações na coloração das folhas mais novas e uma tonalidade arroxeada no caule, contrastando nitidamente com o resto amarelado do limbo (Figura $1 \mathrm{D}$ ). Com o agravamento da deficiência e conseqüente queda dos níveis de clorofila, as folhas tornaram-se totalmente cloróticas e, em seguida, esbranquiçadas, retardando o crescimento das plantas (Figura $1 \mathrm{E})$. As plantas desse tratamento foram colhidas aos 50 dias.

Deficiência de manganês - Os sintomas de deficiência do Mn, na fase inicial, foram menos evidentes, mais facilmente observados nas folhas mais sombreadas, tornando-se mais perceptíveis com a severidade da deficiência (Figura $1 \mathrm{~F}$ ). As folhas mais jovens, aos 55 dias após o início do tratamento, apresentaram-se com esparsas áreas cloróticas adjacentes à nervura principal. Com o aparecimento da deficiência, os pontos cloróticos a necróticos foram se multiplicando sem, contudo, ocasionar a queda das folhas. As plantas deficientes apresentaram, durante um determinado período, desenvolvimento aparentemente normal, com as folhas atingindo dimensões até mesmo maiores quando comparadas às das plantas do tratamento completo. Uma característica bastante interessante observada nas plantas deficientes em Mn foi o engrossamento da parte basal do caule, que acabou por ficar mais espesso do que os caules das plantas submetidas ao tratamento completo.

Deficiência de zinco - Nas plantas cultivadas na ausência de $\mathrm{Zn}$, as alterações morfológicas surgiram aos 35 dias após o início do tratamento, de forma mais pronunciada nas folhas mais jovens. O principal sintoma de deficiência de zinco consistiu na produção de folhas pequenas e estreitas, algumas vezes retorcidas (Figura $1 \mathrm{G}$ ). Foi observado também, além da formação de folhas pequenas e próximas entre si, com áreas cloróticas entre as nervuras, a formação de ramos com internódios curtos, dando o aspecto de "roseta".

Deficiência simultânea de cobre e zinco - Nos tratamentos em que não se adicionaram $\mathrm{Cu}$ e $\mathrm{Zn}$, os primeiros sintomas observados foram os da deficiência de $\mathrm{Zn}$, onde os limbos foliares apresentaram 
uma superfície enrugada/deformada, originando folhas diminutas, cloróticas e com leve crestamento nas pontas. Essas plantas desenvolveram ramos finos com folhas pequenas e mais estreitas, que, no final, se mostraram pendentes, com ápices voltados para baixo (Figura $1 \mathrm{H})$. De modo semelhante ao que foi observado na deficiência de $\mathrm{Cu}$, a falta conjunta de $\mathrm{Cu}$ e $\mathrm{Zn}$ também induziu a emissão de gemas vegetativas axilares múltiplas, originando brotações com folhas diminutas (Figura 1 I)

\section{CONCLUSÕES}

1 - A falta de B, Cu, Fe, Mn e Zn na solução nutritiva levou a um comprometimento no desenvolvimento das plantas, induzindo, inclusive, alterações morfológicas com sintomas característicos de deficiência nutricional de cada nutriente.

2 - O umbuzeiro mostrou-se mais exigente em B, Fe e Zn na fase inicial de crescimento do que em $\mathrm{Mn}$ e em $\mathrm{Cu}$.

3 - A redução na matéria seca total das mudas de umbuzeiro foi influenciada na seguinte ordem: $\mathrm{Fe}>\mathrm{B}>\mathrm{Zn}>\mathrm{Zn}+\mathrm{Cu}>\mathrm{Cu}>\mathrm{Mn}$.

\section{REFERÊNCIAS BIBLIOGRÁFICAS}

ARAÚJO, F. P. de; SANTOS, A. C.; CAVALCANTI, N. B. Cultivo do umbuzeiro. Instruções Técnicas da Embrapa Semi-árido, PetrolinaPE, n. 24. 2000.

CODEVASF. Censo Frutícola: programa fruticultura, relatório das fases produtivas. Disponível: < www.codevasf.gov.br/fruticultura>. Acesso em: jul. 2003.

FERREIRA, D. F. Análises estatísticas por meio do SISVAR (Sistema para Análise de Variância) para Windows 4.0. In: REUNIÃO ANUAL DA REGIÃO BRASILEIRA DA SOCIEDADE INTERNACIONAL DE BIOMETRIA, 45., 2000, São Carlos. Anais... São Carlos: UFSCar, 2000. p. 255-258.
GONDIM, T. M. S.; SILVA, H.; SILVA, A. Q.; CARDOSO, E. A. Período de ocorrência de formação de xilopódios em plantas de umbu (Spondias tuberosa Arr. Cam. ) propagadas sexualmente e assexuadamente. A. Revista Brasileira de Fruticultura, Cruz das Almas, v. 13, n. 2, p. 33-38, 1991.

HOAGLAND, D. R.; ARNON, D. I. The water culture method of growing plants without soil. Berkeley: University Of California Berkeley, 1950. 32p.

MALAVOLTA, E. Micronutrientes na adubação. Paulínia: Nutriplant, 1986.70p.

MALAVOLTA, E.; VITTI. G.C.; OLIVEIRA, S. A. Avaliação do estado nutricional das plantas: princípios e aplicações. Piracicaba: POTAFOS, 1997.319p.

MARSCHNER, H. Mineral nutrition of higher plants. 2. ed. Academic Press, 1995. 889p.

MARTINS, G. C.; MELLONI, R.; CARVALHO, J. G. de. Efeito da omissão de micronutrientes no crescimento de mudas de andiroba (Carapa guianensis Aubl.). FERTBIO, 2000, Santa Maria-RS. Anais... CDRom.

NASCIMENTO, C.E. S.; SANTOS, C. A. F.; OLIVEIRA, V. R. Produção de mudas enxertadas de umbuzeiro (Spondias tuberosa Arruda). Embrapa Semi-Árido, 2000. 13p. (Circular Técnica, n. 48)

PIMENTEL-GOMES, F. Curso de estatística experimental. PiracicabaSP: Nobel, 1990. 468p.

RAIJ, B.V. Fertilidade do solo e adubação. Piracicaba-SP: Ceres/Potafos, 1991.343p.

SALVADOR, J. O.; MOREIRA, A.; MURAOKA, T. Sintomas visuais de deficiências de micronutrientes e composição mineral de folhas em mudas de goiabeira. Pesquisa agropecuária brasileira, Brasília, v.34, n.9, p.1655-1662, 1999.

SILVA, E. B.; GONÇALVES. N. P.; PINHO, P. J. de; CANUTO, R. SILVA. Requerimentos nutricionais do umbuzeiro (Spondias tuberosa Arr. Câm.). FERTBIO. Rio de Janeiro, 2000. Anais ... 